\title{
A simulação computacional no ensino da temática de Terra como corpo cósmico
}

\author{
Nascimento, J. O. do ${ }^{1 *}$; Neide, I. G. ${ }^{2}$; Gonzatti, S. E. M. ${ }^{2}$; Moret, M. $A^{1,3}$ \\ 1 Departamento de Modelagem Computacional, Faculdade de Tecnologia SENAI CIMATEC, Salvador, BA, Brasil. \\ 2 Centro de Ciências Exatas e Tecnológicas - CETEC, Centro Universitário UNIVATES, Lajeado, RS, Brasil. \\ 3 Universidade do Estado da Bahia, Salvador, BA, Brasil.
}

*e-mail: jeffersonascimento@gmail.com

\begin{abstract}
Resumo
Seja na educação básica, educação profissional ou nível superior, os conteúdos físicos ainda são apresentados, muitas vezes, de forma tradicional, sendo reproduzidos a partir de materiais instrucionais de forma estática e pouco contextualizada. Assim, este artigo tem como objetivo apresentar resultados de uma proposta metodológica, para o ensino de Leis de Kepler e Lei da Gravitação Universal de Newton. Estes conteúdos integram a temática de Terra como corpo cósmico, necessária para o ensino de fenômenos astronômicos. Foi utilizado para simulação computacional o software My Solar System, um Objeto de Aprendizagem. A pesquisa de abordagem qualitativa, ocorreu por meio de uma intervenção pedagógica com alunos de uma turma de PROEJA (Educação de Jovens e Adultos integrada à Educação Profissional). Durante o processo de intervenção, verificou-se indícios de aprendizagem significativa por parte dos discentes no que se refere à compreensão dos conceitos supracitados. Assim, é possível argumentar que a proposta desenvolvida apresentou-se como um material potencialmente significativo
\end{abstract}

Palavras-chave: Simulação computacional, Objetos de aprendizagem, Ensino de Física

\begin{abstract}
Be on basic education, professional education or during the undergraduate programs, the physical contents are still presented often in traditional, merely being reproduced from instructional materials so ready and finished. In this paper, we show some results of a methodological approach, based on the cognitive psychology of Ausubel, for thematic teaching of Earth as cosmic body. The data presented are results within the master thesis of the first author. The methodological procedures occurred with learning objects. The software used as tools for computer simulation, in a qualitative research, through an educational intervention with students from PROEJA (National Program of Integration between Professional Education with Basic Education in the form of Youth and Adult Education). Throughout the intervention process, conceptual changes we saw on the part of students and evidence of meaningful learning in motion. So, possibly the proposed methodology, introduced himself as a potentially significant material
\end{abstract}

Keywords: Modeling Computer, Learning objects, Physics Education.

\section{Introdução}

A física é uma disciplina importante, seja na educação básica ou em muitos currículos em nível superior. Contudo, devido à abordagem pedagógica com que é apresentada aos alunos, o resultado nem sempre é satisfatório, ocorrendo em muitas situações a reprovação e a consequente evasão do ambiente de aprendizagem [1]. Esta constatação, faz com que os alunos, quando chegam às universidades e/ou ao mercado de trabalho, levem as deficiências de aprendizagem adquiridas na educação básica [1].
Nessa direção, constatamos por meio de nossas práticas profissionais que, nos diversos níveis de ensino (educação básica e nível superior), os fenômenos astronômicos correspondem a um dos conhecimentos científicos que mais se destacam em serem aprendidos de forma equivocada. Moreira [2] indica que dentro desta temática, as estações do ano, possivelmente, apresentam-se como o fenômeno em que mais ocorrem erros conceituais por parte de alunos e professores. Embora seja do cotidiano das pessoas, a compreensão das estações do ano exige a integração de diferentes conceitos, entre eles, situar a Terra como corpo cósmico e desenvolver um modelo tridimensional para o sistema Sol-Terra $[3,4]$. 
Diante desta realidade, para o entendimento não apenas das estações do ano, mas dos demais fenômenos astronômicos, deve haver por parte do aluno, primeiramente um aprendizado significativo dos conteúdos físicos referentes à temática de Terra como corpo cósmico [4]. Norteados por esse pressuposto, este artigo tem por objetivo apresentar alguns resultados da pesquisa de dissertação de mestrado do primeiro autor, que constituiu uma proposta uma metodológica de ensino dos conteúdos referentes à temática de Terra como corpo cósmico e fenômenos astronômicos (com ferramentas tecnológicas).

Para o presente artigo, apresentamos resultados pela utilização do software My Solar System, que corresponde a um objeto de aprendizagem. De acordo com Nascimento [4] e Nascimento, Neide e Gonzatti [5], há dificuldades no processo de ensino e aprendizagem desses assuntos na Educação Básica e para alguns cursos em Nível Superior (que abrangem Física/Astronomia). Assim, entendemos ser importante investigar as concepções sobre essa temática em uma outra modalidade de ensino, neste caso, com alunos do PROEJA (Programa Nacional de Integração da Educação Profissional com a Educação Básica na modalidade de educação de jovens e adultos).

\section{Aprendizagem Significativa e a temática de Terra como corpo cósmico}

A presente pesquisa está alicerça na aprendizagem significativa de Ausubel. Ela é um processo cujo produto resultante é a aquisição de novos significados pelo aprendiz [6]. Durante o período de aprendizagem, uma nova informação interage de maneira substantiva e também de forma não arbitrária, com subsunçores importantes já presentes na estrutura cognitiva do aprendiz.

Norteados em Ausubel [6], realizamos a investigação de buscar os subsunçores que deveriam estar presentes na estrutura cognitiva do aprendiz, para que a temática de fenômenos astronômicos, pudesse ser ancorada. Encontramos respostas em Nussbaum [3], Nascimento [4], Nascimento, Neide e Gonzatti [5] Nussbaum e Novak [7], Gonzatti [8]. Para estes autores a resposta corresponde à temática de Terra como um corpo cósmico. Para Gonzatti [8] e Nascimento [4], estudar a temática de Terra como corpo cósmico, significa abordála por meio de sua forma, seu campo gravitacional, seus movimentos e os fenômenos astronômicos decorrentes desses movimentos e da configuração do sistema TerraSol-Lua, como por exemplo, dias, noites, estações do ano, fases e eclipses lunares, ou seja, a sua interação com outros astros cósmicos. Diante da necessidade do prévio aprendizado desta temática, destacamos neste artigo os seguintes assuntos: Leis de Kepler e a Lei da Gravitação Universal de Newton, que além integrarem o subsunçor Terra como um corpo cósmico, apresentam mútua importância para este conhecimento prévio, conforme Figura 1:

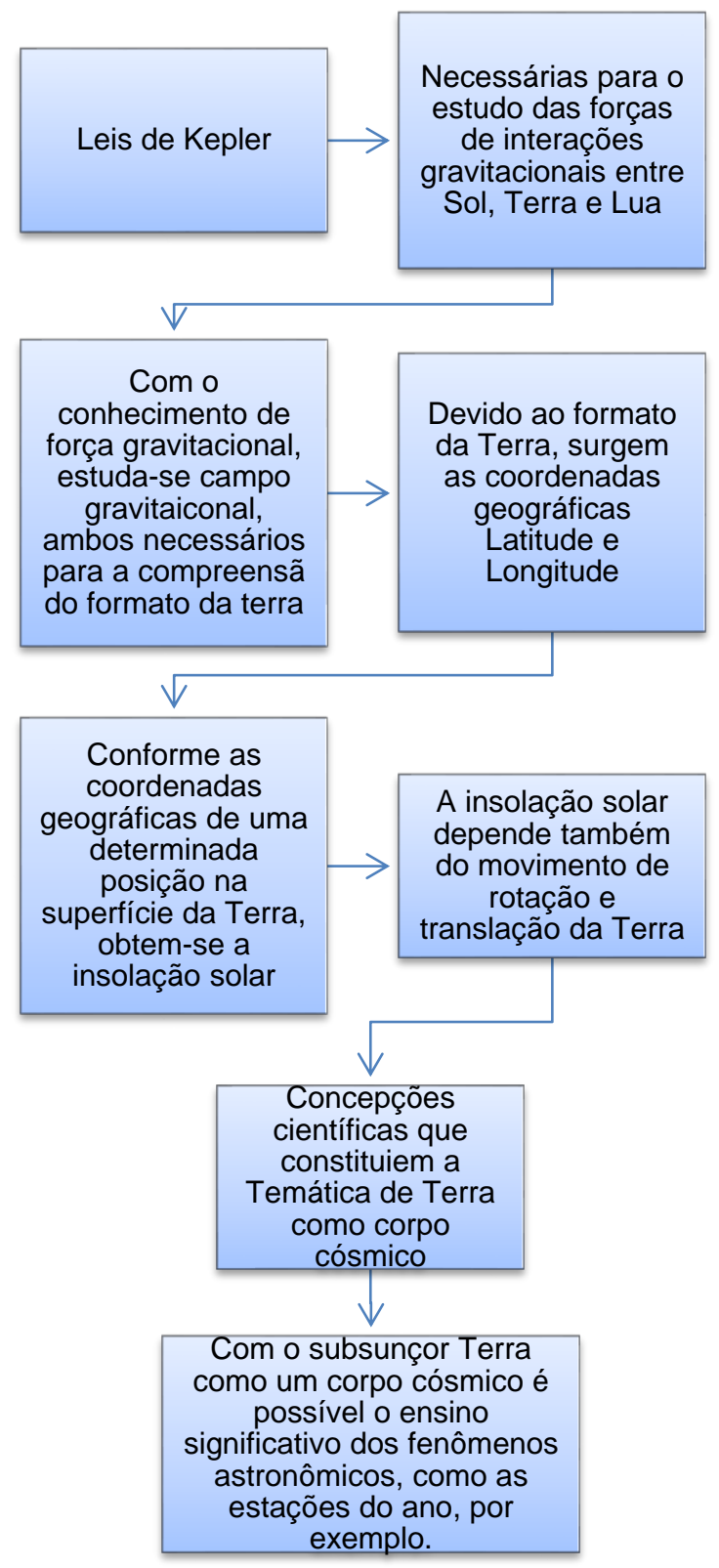

Figura 1 - Importância das Leis de Kepler e da Lei da Gravitação Universal de Newton à temática de Terra como corpo cósmico e os fenômenos astronômicos. Fonte: Adaptado de [9].

Conforme Figura 1, as Leis de Kepler e a Lei da Gravitação Universal de Newton correspondem a conhecimentos fundamentais dentro da temática de Terra como corpo cósmico. Diante dessa observância e a necessidade de explorar os conceitos subsunçores antes do estudo de fenômeno astronômicos, este artigo apresenta alguns resultados de uma proposta metodológica que utilizou o software My solar Systems (um objeto de aprendizagem), para o ensino das Leis de Kepler e Lei da Gravitação Universal de Newton. Para Spinelli [10] esses objetos podem tanto englobar um determinado conceito da ciência a ser ensinada, no caso a Física, quanto toda a teoria a ser abordada e ainda 
"compor um percurso didático, envolvendo um conjunto de atividades, focalizando apenas determinado aspecto do conteúdo envolvido".

De acordo com Araujo [11] os objetos de aprendizagem constituem ferramentas de simulações computacionais. $\mathrm{Na}$ simulação de um determinado modelo físico, é permitido apenas inserir valores e alterar parâmetros e, consequentemente, verificar os resultados em relação as variáveis inseridas [11]. Não há possibilidade de alteração do modelo matemático que originou a simulação, cabendo ao aluno apenas explorá-lo.

O repositório de objetos de aprendizagem escolhido, correspondeu às simulações interativas do Projeto Physics Educacional Technology (PhET), da Universidade do Colorado. O que norteou nossa escolha foi a divulgação científica existente em relação a estas simulações, com expressivos resultados de impacto positivo no ensino de Física, expostos em Arantes, Miranda e Studart [12], dentre outros. Para esses autores, dois fatores são expressivos para a utilização destas simulações do Phet: a facilidade de acesso via internet (disponíveis de forma gratuita, no endereço http://phet.colorado.edu) e a fácil interação pelos alunos.

Os participantes da pesquisa, corresponderam a alunos do PROEJA de uma escola estadual de Educação Tecnológica do Pará. No caso do ensino médio, caracteriza-se pela oferta Integrada (ensino médio e ensino profissional concomitantes), específica para a Educação de Jovens e Adultos (EJA). O público deve ter idade igual ou superior a 18 anos [13]. Trinta alunos com idades entre vinte e cinco e cinquenta e cinco anos participaram da pesquisa. Todos pertenciam a uma turma de PROEJA Técnico em Informática, sendo quatorze homens e dezesseis mulheres, com faixa etária entre 25-55 anos.

\section{Procedimentos metodológicos}

Em busca de possíveis respostas em relação ao Ensino de Física por meio do software My Solar System, alicerçamo-nos em pressupostos da pesquisa qualitativa, com a realização de um estudo de caso. Este estudo pode ser caracterizado por uma visão investigativa ampla, por meio de nuances verificadas em um único, em poucos ou vários objetos de estudo [14]. Orientados pelo supracitado autor, realizamos uma inserção junto ao espaço social pesquisado (sala de aula) e de forma cuidadosa e sistemática, registramos 0 que ocorreu durante a pesquisa, por meio de anotações no diário de campo e do roteiro de questões. Posteriormente realizamos uma análise utilizando as narrativas e transcrições literais captadas dos participantes da pesquisa durante o período de aplicação da proposta metodológica desenvolvida.
A presente investigação faz parte de uma pesquisa estruturada da seguinte maneira: realizou-se um préteste semiestruturado, para verificarmos os conhecimentos prévios dos alunos e orientar o desenvolvimento da intervenção. $\mathrm{Na}$ sequência, realizamos cinco encontros (totalizando 20 horas-aula) como organizadores prévios, que são "[...] materiais introdutórios, apresentados antes do próprio material a ser aprendido, porém, em um nível mais alto de abstração, generalidade e inclusividade do que esse material" [2]. Os conteúdos correspondem aos apresentados na Figura 1. Após estas etapas, realizamos as aulas com ferramentas tecnológicas (Objetos de Aprendizagem e o Software Modellus, com assuntos elencados na Figura 1). Ao fim da pesquisa foi realizado um pós-teste. Devido a extensão da intervenção realizada, ressaltamos que neste artigo, descrevemos um encontro (total de 4 horas-aula), que utilizamos o Objeto de Aprendizagem My Solar System, para o estudo das Leis de Kepler e da Força de interação Gravitacional, em que suas importâncias já foram destacadas no tópico anterior.

\section{Resultados e discussão}

As análises das respostas dos alunos foram realizadas a partir do exercício pertencente ao roteiro elaborado para utilização do software My Solar System, respondidos por eles. Neste artigo, referimo-nos aos discentes do PROEJA por aluno A1, A2, A3 e assim sucessivamente. A seguir, as análises realizadas, baseadas na atividade desenvolvida para a utilização do software My Solar System (Figura 2):

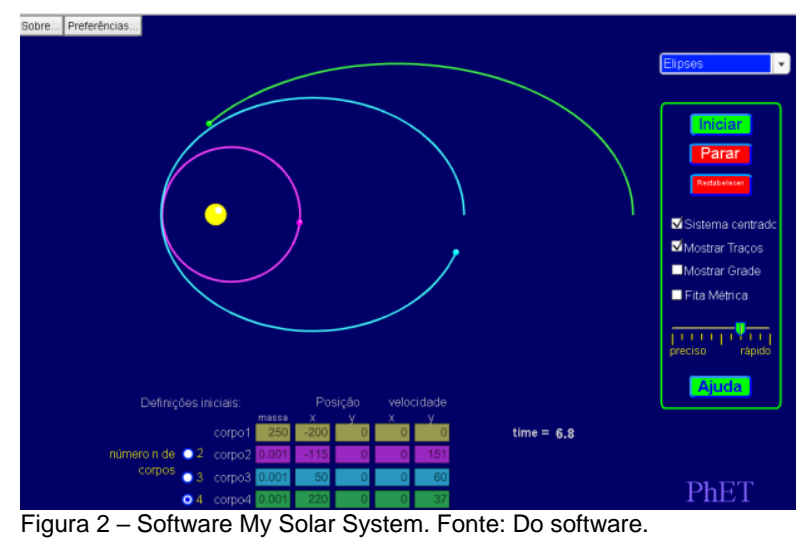

A primeira questão do roteiro solicitava que os alunos reproduzissem, conforme a visualização da simulação (Figura 2), a forma mais coerente com movimento de translação da Terra ao redor do Sol. Todos os alunos cumpriram com satisfação esta solicitação. A segunda questão abordou que, se a trajetória visualizada (em uma segunda simulação), poderia descrever o sistema Sol-Terra. Essa simulação apresentava uma trajetória elíptica, cuja excentricidade era menor que a primeira simulação. Novamente, todos os alunos responderam com a trajetória de menor excentricidade. Para a 
trajetória da órbita da Terra ao redor do Sol, a excentricidade apresenta um valor baixo, 0,016, o que torna essa forma geométrica praticamente circular $[4,8]$.

O último questionamento da segunda questão, requeria dos discentes que explicassem se as estações verão e inverno eram consequências das posições periélio e afélio. Para os alunos A6, A21, A24 e A25, suas respostas respectivamente, são transcritas aqui: "se dá [devido] ao eixo imaginário que tem uma inclinação de 23,5으 que causa verão no extremo e em outro um intenso inverno"; "Não; a causa das estações do ano é a inclinação do planeta"; "Não, porque a causa das estações do ano, é o eixo imaginário, 23,5" e "Não porque a causa das estações do ano é a inclinação da Terra em 23,5". Um total de dezesseis discentes apresentou este padrão de respostas observadas. Conforme Moreira [2] uma das concepções alternativas mais comuns no ensino de ciências, aprendidas de forma equivocada é o fato das pessoas acreditarem "[...] que no verão estamos mais próximos do sol e, no inverno, mais distantes, explicando assim as estações do ano". A este equívoco conceitual cuja definição corresponde ao modelo das distâncias, não foi exposta aqui, por nenhum dos alunos. Nessa perspectiva, Nacimento [4] e Gonzatti [8] destacam que a real causa das estações é a inclinação do eixo imaginário da Terra, em aproximadamente $23,5^{\circ}$, em relação a normal do plano de revolução ao redor do Sol.

$\mathrm{Na}$ terceira questão, o intuito foi de estudar a excentricidade de trajetórias de três planetas ao redor de uma estrela, conforme Figura 2. No primeiro questionamento, cabiam aos alunos indicarem e explicarem quais das trajetórias se assemelharia a da Terra. A seguir, apresentamos as repostas dadas pelos alunos A12, A15 e A24, respectivamente: "O rosa, pois sua excentricidade é muito baixa, referentes aos outros", "rosa porque a excentricidade é muito baixa" e "O rosa, porque é o [que] menos tem excentricidade, muito baixa". Nesta questão, vinte e quatro alunos apresentaram respostas cientificamente adequadas, optando pela trajetória de menor valor de excentricidade, fornecendo um indício de reconciliação integrada. Segundo Moreira [2] a reconciliação integradora ou integrativa "[...] é um esforço explícito, para explorar relações" presentes em diferentes conteúdos programáticos, que o aluno reconcilia as diferenças e semelhanças entre eles (conteúdos).

Como último questionamento da terceira questão, cabia aos alunos explicarem se as estações do ano seriam afetadas pelas formas das trajetórias nos três planetas, devido as diferentes excentricidades. As respostas apresentadas pela maioria dos alunos nos fornecem possíveis indícios de aprendizagem significativa, conforme as respostas dos alunos A21 e A24, respectivamente: "O rosa não interfere, o azul e o verde interferem por causa do alto valor da excentricidade", "apenas no azul e verde pelos exageros da excentricidade". Tal pensamento é alicerçado em Moreira [2], Nascimento [4] e Gonzatti [8], pois apontam na direção de que muitas pessoas ainda admitem que 0 fenômeno das estações é dependente da distância SolTerra (modelo das distâncias), fato este não demonstrado aqui pelos discentes.

Nos dois primeiros questionamentos da quarta questão, os alunos deveriam escolher e explicar em quais situações a velocidade da Terra permanece constante, aumenta ou diminui durante o movimento de revolução, na simulação realizada, para se estudar o periélio e o afélio. Vejamos algumas respostas para a situação de um planeta se aproximar do Sol, dos alunos A6 e A15, respectivamente: " $A$ velocidade aumenta pois a distância é menor e a força gravitacional aumenta também aumenta também a velocidade média; " $Q u a n d o$ - planeta se aproxima do Sol aumenta a força gravitacional e a velocidade no periélio é mais rápida". Transcrevemos também, as respostas dos alunos A16 e A21, respectivamente, para o caso do planeta afastarse do Sol: "Diminui. Por causa da força gravitacional. Porque quanto maior a distância menor é a força gravitacional e a velocidade média diminui"; "Diminui. Porque perto do Sol a força gravitacional é grande e longe a força diminui e a distância aumenta".

Nascimento [4] discute que, para o modelo Sol-Terra, não há a presença da aceleração tangencial. Então, a aceleração resultante no movimento de revolução só apresenta a componente centrípeta, consequentemente a força resultante será centrípeta. Logo, essa força resultante é central, e correspondente a força gravitacional entre a Terra e o Sol. Não cabe à força gravitacional a mudança de velocidade orbital. As explicações dos alunos transcritas anteriormente, indicam a possibilidade de terem raciocinado que a força gravitacional atuaria como a força tangencial no movimento de revolução da Terra, constituindo o agente motriz para a mudança do valor da velocidade. Dos trinta partícipes da pesquisa, dezenove alunos responderam a essa questão seguindo o padrão apresentado anteriormente, nas transcrições.

Um possível fator que pode explicar essa tendência nas respostas dos discentes é que a maioria dos estudantes em diferentes cursos, níveis e idades, apresentam uma concepção de força aristotélica, entendendo que sempre deve haver uma força na direção do movimento e que força e velocidade são diretamente proporcionais $[4,8]$. Embora o enfoque desse artigo não sejam discutir essas concepções de força, é importante notar como os estudantes acionam seus conhecimentos prévios nesse caso, concepções intuitivas e em desacordo com as leis da Mecânica Clássica - para explicar situações distintas. Caberia aos alunos argumentarem, em função da segunda Lei de Kepler, para justificar o aumento de velocidade no periélio e diminuição no afélio, o que não 
ocorreu (Ibidem). Nesse caso, percebemos conceitos e relações que precisariam ser melhor explorados para a construção de concepções mais completas e sistêmicas que evidenciam as conexões entre os conceitos físicos.

O último questionamento do roteiro, ainda em relação as forças de interações entre os planetas e o Sol, solicitava que os alunos optassem entre elas serem de mesma intensidade, maior ou menor, uma em relação a outra. Dezoito alunos apresentaram respostas corretas - as forças de atração entre os astros correspondem a pares de ação-reação, de igual intensidade e sentidos contrários, não se cancelando porque são aplicadas em corpos diferentes (os que participam da interação). 0 aluno A11, ao ler o enunciado, chamou-nos e fez a seguinte pergunta: "Professor, essa aqui é ação e reação né? Depois de tanta força que a gente já viu e calculou aqui, só pode".

Argumentações como as dos alunos A1, A11 e A24, respectivamente, alicerçam-nos para afirmar que responderam de forma correta cientificamente: "Mesmos valores, porque tem ação e reação", "São as mesmas forças, ação e reação", "Mesmos valores e têm sentidos opostos baseado na ação e reação". É possível perceber que os estudantes associam a ideia de ação e reação às forças de interação entre uma estrela e um planeta, o que está em acordo com a concepção científica da reconciliação integradora, conforme a teoria de Ausubel. O Sol e a Terra se atraem mutuamente por meio da atuação da força gravitacional, cujo valor de intensidade e a direção de ação são os mesmos, mas o par de forças apresenta sentidos opostos, o que caracteriza a terceira Lei de Newton (ibidem).

\section{Considerações finais}

Para auxiliar os processos de ensino e aprendizagem das Leis de Kepler e da Lei da Gravitação Universal de Newton, concepções necessárias e pertencentes à temática de Terra como um corpo cósmico, propomos a utilização do Objeto de Aprendizagem My Solar System como ferramentas tecnológicas para o Ensino de Física. Estando o supracitado subsunçor na estrutura cognitiva do aprendiz é possível aprender de forma significativa os fenômenos astronômicos, como as estações do ano, por exemplo. Assim, por meio da metodologia de ensino apresentada, utilizando o Objeto de Aprendizagem My Solar System, verificamos indícios de aprendizagem significativa dos alunos em relação aos temas investigados aqui. Nas argumentações deles retratadas neste artigo, resultantes da intervenção pedagógica, foi evidenciada a ocorrência da reconciliação integradora. Conforme a Psicologia de Ausubel, podemos argumentar que, possivelmente, a metodologia proposta, apresentou-se como um material potencialmente significativo

\section{Agradecimentos}

O primeiro autor agradece à FAPESB, devido ao apoio financeiro parcial por meio de sua bolsa de doutorado (BOL170/2015). O último autor agradece ao CNPq pelo suporte financeiro parcial oriundo de sua bolsa de Produtividade em Pesquisa (No. 304454/2014-1).

\section{Referências}

[1] TEODORO, Vítor Duarte; NEVES, Rui Gomes. Mathematical modelling in science and mathematics education. Computer Physics Communications, v. 182, n. 1, p. 8-10, 2011.

[2] MOREIRA, Marco Antônio. Aprendizagem significativa, organizadores prévios, mapas conceituais, diagramas $\mathrm{V}$ e unidades de ensino potencialmente significativas. I Encontro Regional de Aprendizagem Significativa I ERAS NORTE. UEPA, Belém, 2013. Disponível

em: <http://paginas.uepa.br/erasnorte2013/images/sampled ata/figuras/aprend_\%20signif_\%20org_prev_mapas_co nc_diagr_v_e_ueps.pdf>. Acesso em: 23 abr. de 2014.

[3] NUSSBAUM, J. Children's Conceptions of the Earth as a Cosmic Body: a cross age study. Science Education, New York, v. 63, n. 1. p. 83-93, Jan. 1979.

[4] NASCIMENTO, Jefferson Oliveira do. O Ensino de Física por meio de ferramentas tecnológicas: um estudo de caso com o PROEJA. 2015. 231 f. Dissertação (Mestrado em Ensino de Ciências Exatas) - Centro Universitário UNIVATES, Lajeado, 25 set. 2015.

[5] NASCIMENTO, Jefferson Oliveira do; NEIDE, Italo Gabriel; GONZATTI, Sônia Eliza Marchi. Modelagem e simulação computacional no ensino de Física: Uma proposta de estudo de caso com o PROEJA. In: XXI Simpósio Nacional de Ensino de Física, 2015, Uberlândia/MG. Anais do XXI SNEF, 2015. v. 1. p. 1-8. Disponível em: http://www.sbf1.sbfisica.org.br/eventos/snef/xxi/sys/resu mos/T0527-2.pdf>. Acesso em: 04 mar. 2015.

[6] AUSUBEL, David Paul. Aquisição e retenção de conhecimento: uma perspectiva cognitiva. Lisboa: Plátano Edições Técnicas, 2003.

[7] NUSSBAUM, Joseph; NOVAK, Joseph D. An assessment of children's concepts of the earth utilizing structured interviews. Science Education, v. 60, n. 4, p. 535-550, 1976.

[8] GONZATTI, Sônia Elisa Marchi. Um Curso Introdutório à Astronomia para a Formação Inicial de Professores de Ensino Fundamental, em nível médio. 2008. 260 f. Dissertação (Mestrado Profissional em Ensino de Física) - Instituto de Física, Universidade Federal do Rio Grande do Sul, Porto Alegre, 2008. 
[9] NASCIMENTO, Jefferson Oliveira do.; NEIDE, Italo Gabriel.; GOZATTI, Sônia Elisa Marchi. Objetos de aprendizagem e o Microsoft Excel como ferramentas auxiliares no Ensino de Física. Caderno Pedagógico (online), Lajeado, v. 13, n. 01, 2016. Disponível em: <http://univates.br/revistas/index.php/cadped/article/vie w/1717>. Acesso em 19 ago. 2016.

[10] SPINELLI, W. Os objetos de aprendizagem: Ação, criação e conhecimento. 2007. Disponível em: <http://www.lapef.fe.usp.br/rived/textoscomplementares /textolmodulo5.pdf>. Acesso em: 10 mar. 2015.

[11] ARAUJO, Ives Solano. Simulação e modelagem computacionais como recursos auxiliares no ensino de física geral. 2005. 238 f. Tese (Doutorado em Ensino de Física) - Instituto de Física. Universidade Federal do Rio Grande do Sul, Porto Alegre, 2005.
[12] ARANTES, Alessandra Riposati; MIRANDA, Márcio Santos; STUDART, Nelson. Objetos de aprendizagem no ensino de física: usando simulações do PhET. Física na Escola, 11, n. 1, 27-31, 2010.

[13] BRASIL. Ministério da Educação. PROEJA Programa Nacional de Integração da Educação Profissional com a Educação Básica na modalidade de Educação de Jovens e Adultos. Educação Profissional Técnica de Nível Médio / Ensino Médio. Documento Base. MEC, 2007. Disponível em: <http://portal.mec.gov.br/setec/arquivos/pdf2/proeja_fun damental_ok.pdf>. Acesso em: 12 ago. 2013.

[14] GIL, A.C. Como elaborar projetos de pesquisa. 3 ed. São Paulo: Atlas, 1996. 